\title{
Right coronary artery stenosis unmasking ischemia in a patient with bilateral coronary pulmonary fistulas
}

\author{
Obai Abdullah, Abdallah Mansour, Haytham Allaham, Kul Aggarwal \\ Cardiology Department, One Hospital Drive, University of Missouri-Columbia, Columbia, USA
}

Adv Interv Cardiol 2017; 13, 4 (50): 339-340

DOI: https://doi.org/10.5114/aic.2017.71618

\section{Introduction}

Coronary artery fistulas (CAF) are congenital or acquired formations between the coronary arteries and cardiac chambers or other vascular structures such as the vena cava, pulmonary artery, or veins [1]. Most of these are found incidentally during angiography [2]. Fistulas account for half of all coronary anomalies and are present in $0.002 \%$ of the general population. Coronary to pulmonary artery fistulas comprise $15-30 \%$ of coronary anomaly cases and only $5 \%$ of these involve bilateral coronary arteries [3].

\section{Case report}

A 71-year-old man with hypertension, hyperlipidemia, and smoking abuse underwent single photon emission computed tomography (SPECT) myocardial perfusion scintigraphy (MPI) for exertional chest pain (CCS II) which showed borderline inferoseptal reversible perfusion abnormality based on the SPECT 17-segment scoring system $(\mathrm{SSS}=3, \mathrm{SRS}=0, \mathrm{SDS}=3$ ) (Figure 1$)$. His vital signs were: heart rate $68 \mathrm{BPM}$, respiratory rate (RR) 24/min, blood pressure (BP) $133 / 76 \mathrm{~mm} \mathrm{Hg}$, and $\mathrm{O}_{2}$ saturation of $98 \%$ on room air. He had normal S1, S2 without murmurs, edema or jugular venous distention. Laboratory data were within normal limits. ECG was normal sinus rhythm without ischemic changes. Transthoracic echocardiogram (TTE) revealed normal ejection fraction of $55 \%$, right ventricular systolic pressure (RVSP) of 40-50 $\mathrm{mm} \mathrm{Hg}$, with septal motion consistent with conduction abnormality.

Coronary angiogram was performed and showed two type A lesions in the right coronary artery (RCA) with TIMI 3 flow. One was proximal and severely stenotic. The second lesion was distal and moderately stenotic. He was also found to have two fistulas draining into the pulmonary trunk and arising bilaterally from the both the RCA and left anterior descending artery (LAD) (Figure 1).
We elected to correct the proximal stenosis with a bare metal stent (BMS) due to concerns for non-compliance and we managed the distal stenosis medically. Right heart catheterization ruled out hemodynamic significance of these fistulas with pulmonary artery pressure (PA): $35 / 5 \mathrm{~mm} \mathrm{Hg}$ (normal: $15-30 \mathrm{~mm} \mathrm{Hg}$ systolic, 2-8 mm Hg diastolic), mean 22 (normal: 9-18 $\mathrm{mm} \mathrm{Hg}$ ), pulmonary capillary wedge pressure (PCWP): $10 \mathrm{~mm} \mathrm{Hg}$ (normal: 2-15 mm Hg), cardiac output: $5.7 \mathrm{l} / \mathrm{min}$ (normal: 4-9 l/min), mixed venous saturation: $68 \%$ (normal: 60-80\%). Pulmonary vascular resistance: 2.1 (0.25$2.5 \mathrm{~mm} \mathrm{Hg} / \mathrm{l} / \mathrm{min}$ ) with no "step up" of oxygen saturation from the superior vena cava (SVC) to the right pulmonary artery.

He was followed closely and he remained asymptomatic. Repeat SPECT 3 years later revealed normal ejection fraction (EF) and no reversible perfection abnormality. Transthoracic echocardiogram also was repeated and showed right ventricular systolic pressure (RVSP) of 30$40 \mathrm{~mm} \mathrm{Hg}$ with normal EF.

\section{Discussion}

Coronary to pulmonary artery fistulas involving both coronary arteries are very rare anomalies with few reported cases in the literature $[4,5]$. Concomitant significant coronary artery stenosis can cause the coronary steal phenomenon with resultant myocardial ischemia [6], which was evident in our patient with complete resolution of his symptoms after correcting the proximal RCA stenosis.

Most coronary to pulmonary artery fistulas are asymptomatic, but dyspnea, heart failure, angina due to myocardial ischemia and endocarditis have been reported [2]. Symptomatic patients can be treated with trans-catheter embolization or surgical ligation. Spontaneous occlusion of small fistulas may occur but is rare [6].

\section{Corresponding author:}

Obai Abdullah MD, Cardiology Department, One Hospital Drive, University of Missouri-Columbia, 65212 Columbia, USA, phone: +1 5735299454, e-mail: dr_omfa@hotmail.com

Received: 20.09.2017, accepted: 8.11.2017. 

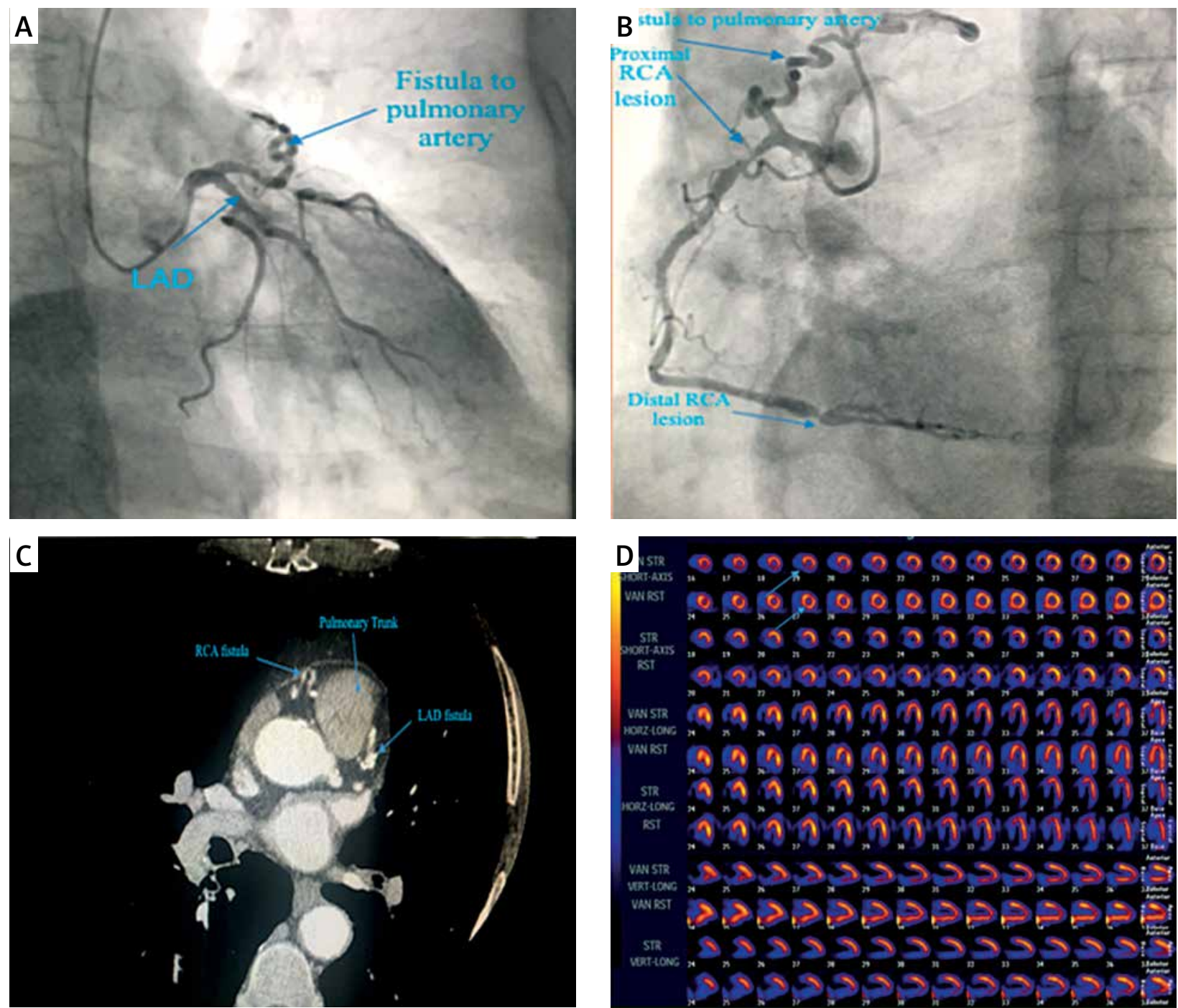

Figure 1. A - Coronary angiography showing tortuous fistula arising from the LAD, B - coronary angiography showing large tortuous fistula arising from the RCA and the high grade proximal stenosis corrected with BMS and distal stenosis managed medically, C - cardiac CT showing bilateral tortuous fistulas draining into the pulmonary trunk, D - SPECT images showing stress defect (arrows)

This paper presents a very rare combination of bilateral coronary arterial fistulas draining into the pulmonary artery that became symptomatic only after the RCA was highly stenosed. Monitoring asymptomatic patients with this anomaly is an acceptable approach as done in our patient [3].

\section{Conflict of interest}

The authors declare no conflict of interest.

\section{References}

1. Ibrahim MF, Sayed S, Elasfar A, et al. Coronary fistula between the left anterior descending coronary artery and the pulmonary artery: two case reports. J Saudi Heart Assoc 2012; 24: 253-6.

2. Raju MG, Goyal SK, Punnam SR, et al. Coronary artery fistula: a case series with review of the literature. J Cardiol 2009; 53: 467-72.
3. Huang YK, Lei MH, Lu MS, et al. Bilateral coronary-to-pulmonary artery fistulas. Ann Thorac Surg 2006; 82: 1886-8.

4. Baim DS, Kline H, Silverman JF. Bilateral coronary artery: pulmonary artery fistulas. Report of five cases and review of the literature. Circulation 1982; 65: 810-5.

5. Pereira da Silva F, Donato P, Donato H, et al. Symptomatic bilateral coronary artery fistula to pulmonary artery in elderly patient. Eur J Radiol Open 2016; 3: 272-4.

6. Vavuranakis M, Bush CA, Boudoulas H. Coronary artery fistulas in adults: incidence, angiographic characteristics, natural history. Cathet Cardiovasc Diagn 1995; 35: 116-20. 